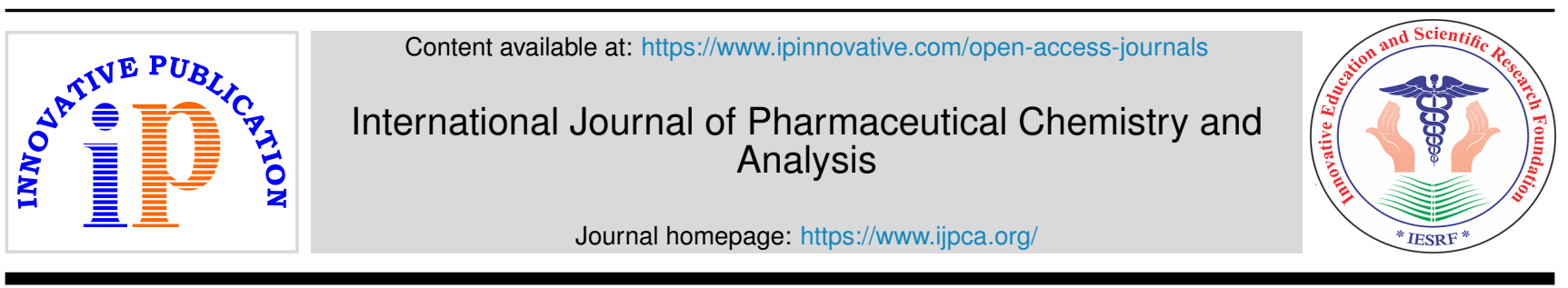

\title{
Review Article
}

\section{Overview on capillary electrophoresis with mass spectrometry: Application in peptide analysis and proteomics}

\author{
Umang Shah ${ }^{1}$,*, Aarti Patel ${ }^{1}$, Rutu Patel ${ }^{1}$, Mehul Patel ${ }^{1}$, Ashish Patel ${ }^{1}$, \\ Mansukh Kavad $^{2}$, Esha Desai ${ }^{3}$ \\ ${ }^{1}$ Ramanbhai Patel College of Pharmacy, Charotar University of Science and Technology (CHARUSAT), CHARUSAT Campus, \\ Changa, Gujarat, India \\ ${ }^{2}$ Sun Pharma Advance Research Center, Vadodara, Gujarat, India \\ ${ }^{3}$ Babaria Institute of Pharmacy, BITS Education Campus, Varnama, Vadodara, Gujarat, India
}

\section{A R T I C L E I N F O}

\section{Article history:}

Received 20-03-2021

Accepted 22-03-2021

Available online 04-05-2021

Keywords:

Capillary electrophoresis

Mass spectrometry

Pharmaceutical applications

Peptide analysis

Proteomics

Intact protein

\begin{abstract}
A B S T R A C T
The pharmaceutical industry and most particularly the biopharmaceutical industry are demanding advancements in analytical techniques. The field of proteomics and peptide mapping needs sensitive analysis and sophisticated instrumentation, which needs hyphenated analytical techniques to be explored. In addition to effective detection and characterization, Due to efficient and selective separation, predominant focus has been drawn to capillary electrophoresis/mass spectrometry (CE/MS) compared to widely used techniques such as slab-gel electrophoresis (SGE), liquid chromatography (LC) and capillary electrophoresis (CE) Several significant advances in CE/MS instrumentation and software have made CE/MS a competitive tool in the last decade to solve a wide variety of analytical and biopharmaceutical problems. This analysis discusses the technological aspects of CE / MS interfaces, analytical separation modes, MS analyzer, recent CE / MS approaches and applications specific to biopharmaceutical. Applications using some of the more common electrophoretic separation modes, such as conventional electrophoresis of the capillary zone (CZE) and capillary isoelectric focusing (CIEF), have been highlighted. The peptide analysis also includes recent studies on capillary electro-chromatography (CEC) / MS and CE-MS applications.
\end{abstract}

(C) This is an open access article distributed under the terms of the Creative Commons Attribution License (https://creativecommons.org/licenses/by/4.0/) which permits unrestricted use, distribution, and reproduction in any medium, provided the original author and source are credited.

\section{Introduction}

An increasing demand for sensible and selective protein analysis analytical techniques are due to recent development in protein chemistry, proteomics and biotechnology. Capillary electrophoresis (CE), slab gel electrophoresis (SGE) and Liquid chromatography (LC) are most popular separation techniques used for qualitative and quantitative determination of protein analysis. ${ }^{1}$ As several samples can be studied simultaneously, SGE is a well-established technology for protein separation and a relatively large number of proteins can be solved using 2D SGE. However, restrictions include relatively long, labour-

\footnotetext{
* Corresponding author.

E-mail address: umangshah.ph@gmail.com (U. Shah).
}

intensive analysis, the need for offline detection and the absence of precision (and automation). The benefits associated with SGE are easy automation, separation capability, and routine linkage, including mass spectrometry (MS) is advantageous for different detection concepts. ${ }^{2}$ On the other hand, because of the complex nature of the proteomes, adverse interactions between proteins and the stationary phase and protein denaturation can seriously impede LC studies in the organic mobile phase. This can decrease the separation efficiency and resolution. Even when proteins and peptides are large biomolecules, column blocking can be a concern. ${ }^{3}$

Short analysis time and limited sample requirements for protein analysis are the desirable characteristics associated with CE. Furthermore, in the case of fused- 
silica capillaries and without a stationary phase, CE tests are carried out under aqueous conditions. This enables protein to be analysed by organic modifiers and/or a stationary process without creating changes to conformity. In addition, CE divider conditions may be selected to avoid protein degradation during analysis under (near) physiological conditions. In conclusion, as CE separation is a characteristic of the compound's loading, size and shape, with small differences in protein size or load necessary to separate the compound, especially with a high $\mathrm{CE}$ efficiency. MS has become one of the most popular and useful techniques for small fragment detection. ${ }^{4,5}$

CE-MS has therefore become an efficient analytical technique that allows the separation speed to be combined with the selectivity and the structural information given by the MS, high-resolution capacity and minimal sample consumption of CE. ${ }^{6}$ Several key advances in CE-MS technologies over the last 10 years have made CE-MS a competitive tool to solve various analytical problems. ${ }^{7-13}$ The application of CE-MS is not limited to peptide analysis, now a day's modern CE-MS method are also used for the profiling of metabolomics. ${ }^{14}$

In various fields of information, study of chiral molecules is of particular importance. The pharmacological or toxicological properties of enantiomers may be different, making CE-MS one of the methods of choice for this type of assay. Furthermore, Armstrong et al. have suggested that enantioselective separations can be used in food and beverage studies for the identification of adulterated foods and beverages, monitoring of fermentation processes and products, age assessment and identification, treatment and storage effects, and evaluation of some co-products of flavor and fragrance. ${ }^{15}$

In the pharmaceutical and biopharmaceutical industries, glycosylation studies (adding a carbohydrate unit to a protein molecule) play a pivotal position. Therefore, study and systematic profiling of such glycoproteins is a crucial parameter for determining their biological activity and protein stability. In this analysis, which is the usual post-translational modification of proteins, the CE / MS approach helps. A effective instrument for the impurity profiling of drugs such as tetracosactide is the CE / MS technique. CE / MS in pharmaceutical review is a modernday saviour. $\mathrm{CE}$ is essential for quality management tools for pharmaceutical entities and products. In the study of intact proteins, CE / MS also has applications, either in the development of methods or in the characterization of biopharmaceutical formulations. In the analysis of analytes such as Recombinant Human Insulin, Growth Hormone, Haemoglobin etc., CE / MS helps Characterization of Metal Protein complexes in another modern CE / MS programme that lets the analyst evaluate the metal protein complex's stoichiometry. ${ }^{16}$
In the study of intact serum proteins, the CE / MS study also has applications that are especially useful for the study and characterization of plasma drugs and their binding to plasma proteins. In biomarker discovery and application, capillary electrophoresis coupled with MS has been successfully used, as it allows the selective detection of small protein peptides. CE-MS enables extremely complex samples to be characterized (such as urine, plasma and other bio fluids). It has a number of uses, many of which concentrate on studies of urinary peptide biomarkers in renal and cardiovascular diseases in particular. The malignancy of the genitourinary system has been another important area of concern. Therefore, CE / MS has tremendous potential for cancer patients in the area of biomarker discovery and clinical application. ${ }^{17}$

In a single amino acid, the majority of variant proteins differ from normal proteins. Peptide maps or "fingerprints" have commonly been used to classify the locations of alteration. Both the direct method and the peptide mapping method of LC- MS have recently been developed as powerful tools for analyzing protein structures and mutations. ${ }^{18}$ It is very appealing to combine the high performance and high speed of CE with the high sensitivity and high selectivity provided by MS detection. CE is very tolerant of complex sample matrices and thus allows for the highly selective identification of compounds in several complex mixtures when combined with MS. In suitable cases, MS identification also helps to enhance the general sensitivity of CE analyses. The strength of incorporating MS detection with any hyphenated approach is that it provides a second dimension of separation. MS is then divided first on the basis of the charge-to-size ratio of the analyte and then, in accordance with capillary zone electrophoresis (CZE), on the basis of its $\mathrm{m} / \mathrm{e}$ ratio. A number of methods of ionisation and coupling have been attempted (it is important to improve methods of ionisation and coupling). ${ }^{19}$ The most popular method for routine coupling of CE with MS is electro spray ionization (ESI). ${ }^{20-22}$

High separation speed of CE coupled with MS detector becomes efficient techniques widely used in food analysis. ${ }^{19}$ In general, the analysis of analytical results can be clearer if a separation strategy is combined with MS. ${ }^{11,13}$ As a result, the technique of electron spin ionisation has emerged as a highly useful technique that allows direct linkage with electrophoretic separation techniques. ${ }^{23}$ To obtain fragments of highly complex target compounds, collisionally induced dissociation can be used. The Instrumentation of CE with MS is shown in Figure 1.

MS identification for $\mathrm{CE}$ has been aggressively sought in recent years, because MS is deemed to be more universal than UV absorption. MS's selectivity and accuracy compensate for differences in the analytes' migration times, an issue frequently encountered in CE. Apart from molecular weight and structural information, MS detection 


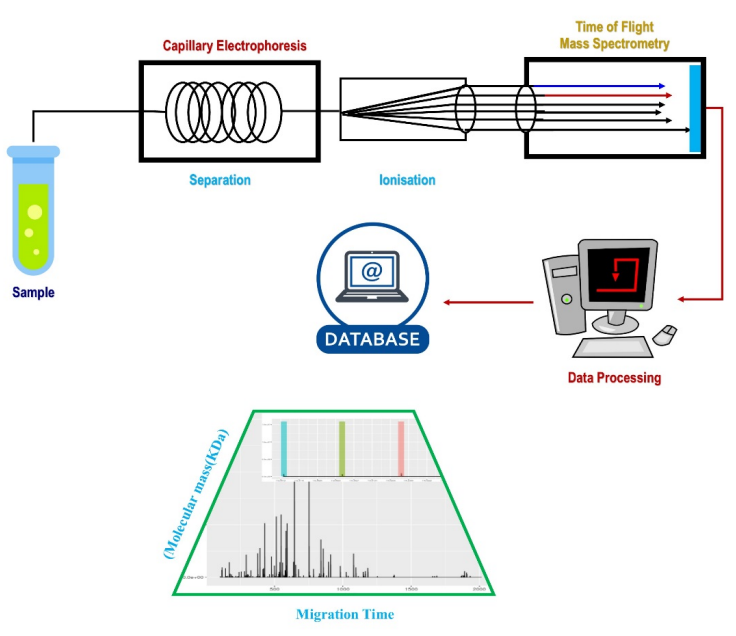

Fig. 1: Instrumentation of CE with MS

also provide information about co-eluting fragments of the target compounds which leads another dimension of separation efficiency of the CE-MS. Low attomole to femtomole concentrations can be detected by MS hyphenated with other efficient separation techniques, which simplify the analytical result with increasing detection limit. Due to these advantages, CE-MS is widely reported technique for peptide analysis compared to other available techniques. ${ }^{24-26}$

The CE/MS coupling has achieved a substantial maturity stage in the past few years. CE / MS interfaces and applications are detailed in several review papers. This report highlights the significant advances in CE / MS that have taken place during the last four years. ${ }^{9,27}$ Applications using some of the more common electrophoretic separation modes have been illustrated, such as classical electrophoresis of the capillary zone (CZE) and capillary isoelectric focusing (cIEF). Latest work on capillary electro chromatography (CEC)/MS is also being considered. ${ }^{28,29} \mathrm{~A}$ variety of different types of mass analyzers have been coupled to $\mathrm{CE}$, including triple quadruple (QQQ), Fourier transform ion cyclotron resonance (FT-ICR), ion trap (IT) and time of flight (TOF). ${ }^{30,31}$ ESI is considered to be the method of choice for interfacing CE with MS because it allows molecules to be transferred directly from the liquid phase to the gas phase. ${ }^{32,33}$ As a unique characteristics given by CE include low consumption of samples/reagents and flexibility, fast analysis. Therefore, CE-MS has become an effective separation and identification technique for the complex peptide and other biomolecules analysis. ${ }^{34-38}$

\section{Interfaces}

A CE separation's effectiveness depends on the CE running buffers, which typically have high ionic strengths and low volatility components. To get good and stable ESI signal, volatile buffers with low salt concentration are preferred. The flexibility of buffer selection is also limited by the CE / ESI-MS interface architecture. While adding the fewest physical and chemical issues, an optimized interface can have good electrical communication. For CE / ESI-MS coupling, three types of interfaces are currently used-sheathless, liquid junction, and coaxial liquid sheath flow. ${ }^{39,40}$

\subsection{Electrospray Interface (ESI)}

At present, electrospray is the most commonly used interface for CE / MS, since this soft ionization approach enables the analytes to be transferred directly from CE to MS and provides a reasonably simple way to close the electrical circuit that $\mathrm{CE}$ requires to work. In addition, this ionisation technique allows multi-charged ions to be formed, which is very useful given the limited mass range of some MS analyzers, taking into account the MS analysis of large peptides. In spite of these benefits, to successfully create this coupling, two problems still have to be solved. An additional restriction on the high volatility required of the compounds used in the electrolyte sense must be considered in order to make them compatible with the formation of sprays. Three different ESI interfaces have been developed to solve these issues. ${ }^{10,39}$

\subsubsection{Sheath-flow interface}

Smith and his colleagues first introduced the use of an interface sheath liquid and it generally consists of the use of three coaxial tubes that supply the analytes, the nebulization gas and the liquid sheath. As it will serve as an external flow to boost the spray, the liquid sheath will have two distinct functions and will also shut down the electrical contact at the capillary outlet that acts as the second electrode.

Stable sprays are obtained by using this proven setup. In addition, since a great range of buffers can be used, it offers great flexibility. Similarly, while this setup's robustness is greater compared to other setups, as sensitivity is lower if diluted the analytes by the sheath liquid. ${ }^{6}$ An important work focused on the use of chemometric methods was carried out by Nilsson et al to determine the effect of several parameters while using a sheath flow interface. They found that better sensitivity could be obtained with narrower capillaries. In addition; efficiencies were increased when 25 $\mu \mathrm{m}$ ID capillaries were used in conjunction with low sheath flow rates. ${ }^{41}$

\subsubsection{Sheathless interface}

Olivares et al. have evolved the sheathless interface, whereas sharpened CE tip was used in its most recent edition. ${ }^{3}$ The piece of gold wire or metal coating frequently used to obtain high voltage ESI at CE capillary tip. The 100 percent good ESI spray stability achieved in aqueous solutions, when the 
ESI emitter is coated with gold. The coating technique is very crucial to decide lifetime of gold coated CE tips and its consistency. Vapor deposition or sputtering processes produce unstable coating that can be removed by electric and physical means. If $\mathrm{Ni}$ or $\mathrm{Ni} / \mathrm{Cr}$ alloy plating is directly applied to silica before gold coating, which enhances gold adhesion to capillary, this gold sputtering and electroplating combination is the most powerful method developed by Kelly et al. ${ }^{26}$

Theoretically, the sheathless interface is the simplest to connect $\mathrm{CE}$ to nano-or microelectrospray. The combination results in high efficiency of ionisation and low limits of mass detection. The signal to noise values for CE / micro-ESI-MS can be increased from 25 to 50 fold. The sheathless interface uses only one CE/MS capillary and therefore several functional problems arise. Second, to ensure comparable migration times and ESI stability, the tip diameter should be carefully considered. ${ }^{26,40,42}$

Capillary columns undergo many changes, such as pulled tips, gold coating at the capillary tips, and chemical coating of the inner walls. This architecture combines into one circuit the electrical circuits CE and ESI. A modification of the sheathless interface has been suggested by Masereeuw et al. to prevent the use of gold-coated tips. It is necessary to discard the entire capillary if one adjustment fails to work properly. ${ }^{43} \mathrm{~A}$ comparison of the graphite-coated sheathless interface with the sheath-flow-interface revealed that the LOD values were similar. The reproductiveness with the sheathless interface was slightly less than the sheath-flow interface. ${ }^{43}$

\subsubsection{Liquid junction interface}

Henion and colleagues established the liquid junction interface first. The interface uses a T-section that makes an electrically attached fused-silica capillary to the ESI emitter through an electrolyte in the buffer reservoir. The gap from the capillary to the transmitter is $20 \mu \mathrm{m} .{ }^{44} \mathrm{~A} \mathrm{CE}$ (physically and electrically) capillary interface has the advantage of being partially isolated from the ESI transmission. The theoretical plate number of 300,000 plates per metre has been achieved by efficiency of separation. Worse alignment of the $\mathrm{CE}$ and the emitter capillaries can lead to major peaks and efficiency loss. The loss of separational effect can be negligible due to the highest expansion if the interface is correctly built. ${ }^{9}$

Foret and colleagues developed an interface with the subatmosphere using a liquid interface with the micro-ESI edge of a substitute. The low pressure in the ESI area led to transportation of samples via the ESI needle without positive pressure at the liquid crossroads. ${ }^{45}$

The liquid interface device in which spray fluid is hydrostatically induced by gravity from a small electrolyte reservoir has been developed by Fenali et al. ${ }^{46}$ Under these conditions, an effective, reproducible and stable electrospray was provided by the CE-MS process, resulting in good sensitivity levels which allowed $\mathrm{ng} / \mathrm{ml}$ of peptides to be detected. The authors, however, say that the use of narrower electrospray tips should still be possible to further boost the performance. ${ }^{41,46,47}$

\section{MS Analyzers}

The wide variety of mass analyzers such as single and triple quadruple, time of flight and ion trap as well as some expensive analyzer have used for peptide analysis with some more expensive analyzers like quadruple flight time MS, ${ }^{48-50}$ Hadamard flight time MS, ${ }^{51}$ Fourier transform ion cyclotron resonance MS (FTICR-MS) etc. Due to lower price, small size and ease of operation kind of characteristics quadruples are most widely used analyzer in conjunction with CE. But their low resolution and sensitivity and mass range problems encountered while peptide analysis. While TOF analyzer is most efficient than quadruples in peptide analysis, as it has good scanning speed, sensitivity and resolution with wide mass range. Ion Trap is often used in protein analysis with all features of TOF because of the costeffectiveness of TOF. In addition, MS/MS studies with IT which is particularly interesting for peptide sequencing, are also possible. ${ }^{52-54}$

Several MS analyzers together with CE, like off line CE-MALDI-TOF-MS, which fall outside the scope of this study, have been compared in a Zürbig et al. In the online CE-ESI-MS couplings analysed for this analysis, the authors showed that the best results were obtained using the FTICR Method, while the QTOF analyser succeeded in sequencing polypeptides and achieved better results than simple analyzers such as IT. ${ }^{55}$ Mass analyzers must be able to cope with many analytes arriving at the same time. It is also beneficial to have a wide dynamic range and a high degree of sensitivity. Extremely precise $\mathrm{m}$ / $\mathrm{z}$ measurements are often used to classify the sample components. The duty period of the analyzer should be long, so that few ions are lost, and the time of collection of the mass spectrum should be short. Irrespective of the choice of a mass analyser, sensitivity can be improved using an ion funnel in instruments with advantageous atmospheric pressure inlets. ${ }^{56}$

The ESI-TOF-MS working on the principle based on orthogonal extraction the incoming ion beam is widely used for ion extraction ${ }^{52}$. Such devices could generate thousands of mass spectrums per second, although the acquisition rate of spectrum cannot be sustained if the equivalent ratio $\mathrm{S} / \mathrm{N}$ is unobtainable. An alternative to the technique of ion extraction is the transformation of TOF-MS by Hadamard, which allows for even higher repetition rates between pulses of extraction to be less than the time necessary to record a spectrum (i.e. to overlap mass spectrum). A process like this has recently been observed with nine peptide CZE-ESI-TOF-MS separation. ${ }^{57}$ By incorporating ion trap 
accumulation, ESI-TOF-MS aims to provide maximum ion usage efficiency; the ion trap is used for TOF analysis to capture ions, periodically ejecting ions into the mass analyser. $^{58}$

Hofstadler et al. reports the CE-ESI-FTICR-MS system for the separation of trypsin-digested protein standards with one mass spectrum every six seconds. However, data processing took more time. ${ }^{59}$ Senko et al. have developed an ion accumulation method externally from the FTICR cell in a linear ion trap. In this respect, gas is prevented and the efficacy of ion applications is improved. ${ }^{60}$ Belov et al. recently created the 'DREAMS' approach by using a linear quadruple ion trap to increase the dynamism of the FTICR range. ${ }^{61}$ High removal of ions allows longer aggregation periods for smaller organisms to increase their ratio $\mathrm{S} / \mathrm{N} .{ }^{61}$

\section{CE Separation Modes for the analysis of Peptides}

Up to now, three main modes, CZE, CIEF and CEC, have been employed for evaluating peptides by CE-MS. Additional modes such as MEKC and CGE are either not compatible or not suitable for separation of peptides.

\section{1. $C Z E-M S$}

In peptide CE-MS analysis, Capillary Zone Electrophoresis (CZE) is widely adopted technique, where peptides are differentiated by choosing MS compatible background electrolytes composed of formic acid, acetic acid and/or ammonium hydroxide, on the basis of their various $\mathrm{m} /$ $z$ ratios. ${ }^{62}$ There is a large number of CE-MS works in this sense in which this simple CZE mode is used to isolate and assess peptides with a global positive charge, along with low pH background electrolytes. ${ }^{63,64}$

\section{2. $C E C-M S$}

Capillary electro-chromatography (CEC) can be regarded as a conglomerate technique that combines HPLC and CE characteristics. Analytes are differentiated in this $\mathrm{CE}$ mode by the same concepts as in HPLC, but the driving force in this case is electro-osmotic flow. Because of the difficulty of making and using the CEC columns, their price and low robustness, this mode is less used than CZE, primarily when dealing with actual samples. On the positive side, CEC enables the use of highly MS compatible BGEs and, as has also been shown for peptides, provides the separation of neutral and charged compounds via their interaction with the stationary phase. ${ }^{65}$ Thus, Gucek et al. were able to obtain sensitivity values at the end of a CEC column packed with $\mathrm{C} 18$ for the various selected peptides connecting CEC to $\mathrm{MS}$ in the attomole range by means of a conductively coated tip. With this set-up, without using any extra sheath fluid, the authors were able to obtain a safe spray. ${ }^{66}$

\section{3. $C I E F-M S$}

The capillary isoelectron concentration (CIEF) technique for the separation and isolation of proteins and peptides, as well as other amphoteric compounds, is a high-resolution technique compared to $\mathrm{CZE}$ and $\mathrm{CEC}$. In this technique peptides are separated by their $\mathrm{pI}$ values in a $\mathrm{pH}$ gradient created by carrier ampholytes under the electrical voltage effect. But low volatility of ampholytes is a challenge for MS coupling for the same different methods have been proposed to solve this problem. ${ }^{67}$ In a work by Kuroda et al, for example, CIEF-MS was used to measure human peptides. The concentration of the carrier ampholytes was optimised in this work as a compromise between the optimum resolution and the optimum efficiency of ESIMS ionisation, achieving detection limits that are ten times lower than those reached by UV detection. ${ }^{68}$

\section{Applications of CE-MS in Peptide Analysis}

\subsection{Capillary Zone Electrophoresis - Mass Spectrometry}

Smith et al. demonstrated that proteins could be readily analysed with CZE-ESI-MS. Their research was the point of departure for the discovery and application of CZE with MS detection for intact protein analysis. Below is an overview of the CZE-MS protein that allows for subdivision into interfaces based on ESI, MALDI and ICP. ${ }^{69}$

\subsubsection{Electro-Spray Ionization}

The CZE is the simplest CE mode while in protein MS, ESI is most popular. Not surprisingly, in intact proteins, CZE-ESI-MS is the most widely used in CE-MS. CZEESI-MS was first applied to analyse model proteins. Later, its uses grew to include more complex analytical problems like isoform identification, biomarker screening as well as single cell study. To recognise potential biomarkers for some diseases, Mischak et al. worked and published various studies on the screening of different body fluids. Urine ${ }^{70}$ was primarily investigated, but serum, ${ }^{71}$ plasma $^{72,73}$ and cerebrospinal fluid were also analysed. The CZE-ESI-MS data were provided by plotting migration times against their molecular masses of the observed constituents, resulting in two-dimensional graphs. Possible biomarkers were identified by comparing the graphs of diseased and healthy volunteers.

Because of the comparatively low concentrations, compared to hemoglobin, the study of carbonic anhydrase I and II in RBCs is very difficult. The CZE-ESI-MS haemoglobin and carbonic anhydrase studies have been demonstrated by Moini et al. ${ }^{74}$ The haemoglobin and carbonic anhydrase I chains were possible to separate and detect, but carbonic anhydrase II chain was not detected due to low concentration. 
Stutz et al. have developed CZE-ESI-MS method in which different clinically important metal binding protein pre concentrated by iso-tachophoresis protein steps. Where they could succeed to identified five metal binding proteins by using background electrolytes such as formic acid with detection limit lower to sub-femtomole per litre. This method seems interesting, but has not been used for actual samples until now. ${ }^{75}$

\subsection{CE-MS Using Bare Fused Silica Capillaries}

A good technique for peptidomics has been shown to be CE-MS. So, the discovery of biomarkers is play vital role in peptidomics. As peptides have already been shown, certain ongoing malfunctions or diseases of the organism could be revealed. ${ }^{37}$ Therefore the identification of new biomarkers is very important to aid in diagnosis. ${ }^{70,76}$ A CE ESI-TOF instrument was used by Kaiser el to determine a polypeptide pattern. The study of patterns may not only suggest differences in certain diseases, but also in the stage of a disease. CE-MS has been shown to be an important analytical tool that could substantially lead to an unambiguous diagnosis based on polypepide pattern analysis, the authors say. ${ }^{77}$ Protein identification through analyses of peptides produced following the biopolymer's enzyme digestion including analysis of protein modifications is one of the main uses of CE-MS in proteomic/peptidomics research. ${ }^{78,79}$

The normal generation of unintended peptide fragments presents a major limitation to overcome this issue, the use of theoretical models to simulate peptide activity in CE may be very useful. It has been demonstrated that the use of CE-MS in combination with bare silica capillaries is a very useful analytical tool for the study of peptide hormones. It can also be used to identify microorganisms in small quantities. ${ }^{80}$

A theoretical model was also developed to connect the sequence of peptides effectively with their electrophoretic behaviour. The efficacy of this model was demonstrated by the huge success in CZE-MS in analysing all of the peptides obtained in one cycle. This model was later examined by comparing the particulars of its slitting to investigate the equivalence of natural and recombinant enzymes. ${ }^{81-83}$

\subsection{Chip-based electrophoresis combined with mass spectrometry}

New CE-MS technology based on chips is also a growing field, as miniaturisation is now a major focus for scientists. The CE on a chip can generally be highly flexible in combining various analytical steps, shorter analytical times, lower sample and reactant consumption and high efficiency. At the same time as this great interest in chip-systems new devices are being developed to connect them to MS instruments. ${ }^{83}$
Karger and colleagues have therefore used on-chip CEMS method demonstrating a modern concept including sample inlet ports, separation channel, interface chip and liquid junction MS and electrospray capillary insertion guide channel. Where peptides were chosen to evaluate efficiency of the developed system and peptides were readily separated in a $4.5 \mathrm{~cm}$ on-chip separation tunnel in the region of attomole with achievable detection limit. ${ }^{82,83}$ Combination of micro fluidic CE systems with mass spectrometric detection is one of the best chip based analytical tool, where sample analysis speed and efficiency can be increased with low cost, weight and size of instrument. ${ }^{84,85}$ The main application of chip-based CE-MS method is protein digestion in the field of peptide analysis with intact protein analysis has also been mentioned in some cases. CZE /CIEF and ESI-MS / MALDI-MS integrated onchip CE combined with MS are generally adopted method for intact protein analysis. Whereas glass, ${ }^{81,86}$ quartz $^{87}$ polycarbonate, ${ }^{88}$ polymethyl methacrylate and polyester are used as chip material, mostly in combination with capillary coatings to minimize protein adsorption.

\subsection{CE-MS using on-line pre-concentration techniques}

A crucial problem associated with CE-MS peptidomics is the adequate sensitivity to carry out study with low concentrations of these peptides in real samples. In the CEMS coupling, due to several factors, the good sensitivity given by MS instruments is reduced. ${ }^{89}$

1. The capillary can inject very low samples, without affecting the efficacy and resolution of the separation and, as a result, the ESI interface is reached by a very limited number of analytes.

2. The constant need for additional sheath liquids to obtain a safe spray which reduces the sensitivity due to frequent dilution

3. As a loss is commonly observed, the effect of ionisation and solution transfer to the MS analyzer must also be taken into account.

To address above limitations, different techniques have been developed to pre-concentrate the sample before ESIMS analysis, whereas sample stacking is one of the best technique. ${ }^{89}$ For peptide analysis, some on-line preconcentration devices based on solid phase extraction (SPE) were also used. ${ }^{90}$ Thus, Janini et al. created new design with capillary of $20 \mu \mathrm{m}$ ID using one of these devices for a regular peptide mixture as shown in Figure 2. Where peptide analysis can be done within 15 min and SPE cartridge can easily replaced. ${ }^{91}$

Chien and Helmer have proposed first field amplified sample injection system as another pre-concentration process used in peptidomics. It is based on the use of two separate buffer solutions for filling the capillary separation, typically at the identical $\mathrm{pH}$ with varied 


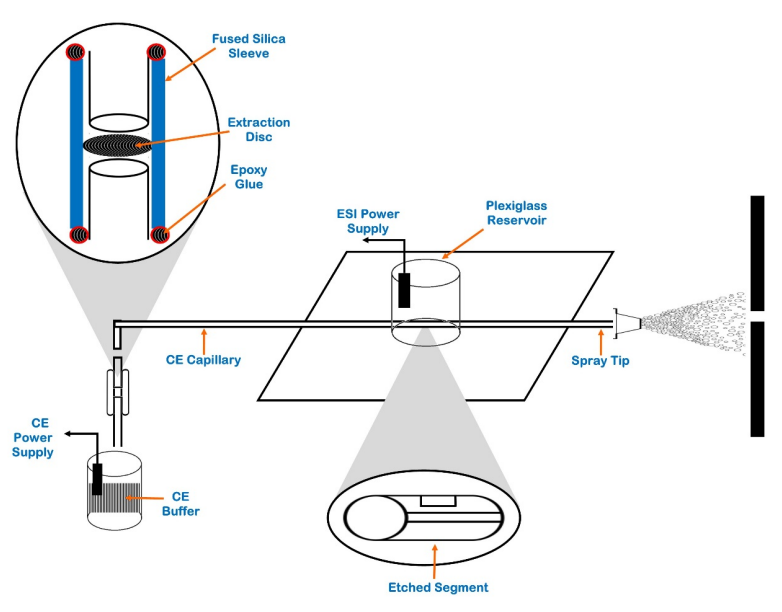

Fig. 2: Schematic diagram of the CE capillary with on-column mSPE cartridge sheathless ESI-MS interface

concentrations. Under these conditions, more than 3000 times the sensitivity increase was obtained as a result of this injection procedure. Sub-nanomolar concentration ranges for the peptides studied could be detected. ${ }^{92-94}$ Larsson and Lutz were able to raise the injection volume by up to $0.9 \mu \mathrm{l}$, where they used transient iso-tachophoresis (transient-ITP) technique to address the low sensitivity issue in CE-MS. It is possible to increase the injection volume substantially by using this technique without losing performance and resolution. ${ }^{94}$

\section{Conclusion}

An increasing demand for separation methodologies that allow protein characterization has been observed over the last few years. This is particularly true in the pharmaceutical sector, where proteins as a drugs are a growing in number. Some of the benefits of CE over LC in this field are known by researchers in academia and businesses. It is not surprising that the number of reported publications of intact proteins are increasing in the field of CE-MS. The main objective of the studies was clearly indicated about feasibility of intact protein analysis for CE-MS and further to explore methodologies for interfaces using models. CEMS has started to be increasingly used for real world applications in the protein field after this step in addressing technical problems. The increasing availability of high resolution mass spectrometers, such as TOF and FTICR instruments, for researchers is an important element of this development. This enhanced the accuracy and accuracy of the detection of protein mass.

New technologies based on this methodology are also accessible as the number of applications grows per year. Thus, as seen in the current review, faster, more powerful, reliable and responsive applications for CE-MS have been developed. Some modifications are still needed, however, before this technique can be used as a routine. Future research is therefore expected to concentrate on creating more effective and stable interfaces capable of providing higher ionisation yields, including new solutions for efficiently interfacing CE and MS without introducing sheath flows by building more powerful and durable sheathless interfaces. Besides, as well as the multidimensional methods, chip-CE-MS will remain of great interest. Production of new equipment for the HPLC interface and

CE-MS will also find fantastic feasible implementation in a stable and reliable way in order to achieve absolute orthogonal separations. The advancement of multidimensional methods, such as CE-MS, and the number of their applications will rise in complex real samples, including the current topic of work, peptide analysis and peptidomics. In this sense a strong area of application for the still rising proteomics / peptidomic markets will unquestionably find the widespread separation potential of multidimensional techniques.

\section{Source of Funding}

None.

\section{Conflict of Interest}

None.

\section{Acknowledgements}

Authors are thankful to Ramanbhai Patel College of Pharmacy, constituent institute of Charotar University of Science and Technology, Changa, Gujarat, India for providing necessary infrastructure.

\section{References}

1. Issaq HJ. The role of separation science in proteomics research. Electrophoresis. 2001;22(17):3629-38. त01:10.10021522 2683(200109)22:17<3629::a1d-elps3629>3.0.co;2-0.

2. Smith RD, Olivares JA, Nguyen NT, Udseth HR. Capillary zone electrophoresis-mass spectrometry using an electrospray ionization interface. Anal Chem. 1988;60(5):436-41. 10:0.102 /ac00156a013.

3. Olivares JA, Nguyen NT, Yonker CR, Smith RD. On-line mass spectrometric detection for capillary zone electrophoresis. Anal Chem.

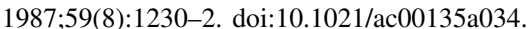

4. Fröhlich T, Arnold GJ. Proteome research based on modern liquid chromatography - tandem mass spectrometry: separation, identification and quantification. $J$ Neural Transmission. 2006;113(8):973-94. [0i:-10.007/s00702-006-0509-3].

5. DeLaney K, Sauer C, Vu N, Li L. Recent Advances and New Perspectives in Capillary Electrophoresis-Mass Spectrometry for Single Cell “Omics". Molecules. 2018;24(1):42. 101:03300/molecules2400042.

6. Smith RD, Barinaga CJ, Udseth HR. Improved electrospray ionization interface for capillary zone electrophoresis-mass spectrometry. Anal Chem. 1988;60(18):1948-52. 10:10.102 /ac00169022.

7. Cole RB. Electrospray and MALDI Mass Spectrometry: Fundamentals, Instrumentation, Practicalities, and Biological Applications. Wiley; 2010. 
8. Frazier RA. Review Recent advances in capillary electrophoresis. Electrophoresis. 2001;22:4197-4206.

9. Banks JF. No TitleRecent advances in capillary electrophoresis/ electrospray/mass spectrometry. Electrophoresis. 1997;18:2255-66.

10. Tomer KB. Separations Combined with Mass Spectrometry. Chem

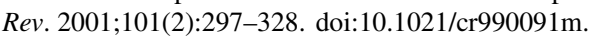

11. Brocke A, Nicholson G, Bayer E. Recent advances in capillary electrophoresis/electrospray-mass spectrometry. Electrophoresis. 2001;22(7):1251-66. [0i: $10.002 / 1522-$ 2683(200105)22:7<1251::aid-elps1251>3.0.co;2-9

12. Moini M. Capillary electrophoresis mass spectrometry and its application to the analysis of biological mixtures. Anal Bioanalytical Chem. 2002;373(6):466-80. 101:10 - $001 / \mathrm{s} 00216-002-1283-1$

13. Schmitt-Kopplin P, Frommberger M. Capillary electrophoresismass spectrometry: 15 years of developments and applications. Electrophoresis. 2003;24(2223):3837-67. doi:10.1002/elps.200305659

14. Zhang W, Hankemeier T, Ramautar R. Next-generation capillary electrophoresis-mass spectrometry approaches in metabolomics. Curr Opin Biotechnol. 2017;43:1-7. do1:10.1016/].copb10.2016.07.002

15. Armstrong DW, Chang CD, Li WY. Relevance of enantiomeric separations in food and beverage analyses. J Agricultural Food Chem. 1990;38(8):1674-7. 001:10.1021/jt00098a010

16. Chowdhury SK, Katta V, Chait BT. Electrospray ionization mass spectrometric peptide mapping: A rapid, sensitive technique for protein structure analysis. Biochem Biophys Res Commun. 1990;167(2):686-92. [01:10.1016/0006-291х(90)92080-].

17. Latosinska A, Siwy J, Mischak H, Frantzi M. Peptidomics and proteomics based on CE-MS as a robust tool in clinical application: The past, the present, and the future. Electrophoresis. 2019;40:2294308. doi:10.1002/elps.20190009].

18. Huang EC, Henion JD. LC/MS and LC/MS/MS determination of protein tryptic digests. J Am Socr Mass Spectrom. 1990;1(2):158-65. doi:10.1016/1044-0305(90)85052-n

19. Simó C, Barbas C, Cifuentes A. Capillary electrophoresis-mass spectrometry in food analysis. Electrophoresis. 2005;26(7-8):130618. 001:10.1002/elps.200410108,

20. Mikkers FEP, Everaerts FM, Verheggen T. Concentration distributions in free zone electrophoresis. J Chromatography A. 1979;169(C):1-10. do1:10.1016/0021-9673(75)85028-x

21. Jorgenson JW, Lukacs KD. Zone electrophoresis in open-tubular glass capillaries: Preliminary data on performance. J High Resolution Chromatography. 1981;4(5):230-1. 001:10.1002/]hrc.1240040501.

22. Cherkaoui S. Clinical and Forensic Applications of Capillary Electrophoresistle. 1st ed. Mohammad AA, editor. Springer; 2001.

23. Macià A, Borrull F, Calull M, Aguilar C. Determination of some acidic drugs in surface and sewage treatment plant waters by capillary electrophoresis-electrospray ionization-mass spectrometry. Electrophoresis. 2004;25(20):3441-9. 10i:10.1002/elps.200406067.

24. Wu JT, Qian MG, Li MX, Zheng $\mathrm{K}$, Huang $\mathrm{P}$, Lubman DM. On-line analysis by capillary separations interfaced to an ion trap storage/reflectron time-of-flight mass spectrometer. $J$

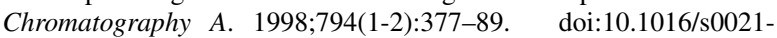
9673(97)00934-5.

25. Figeys D, Oostveen I, Ducret A, Aebersold R. Protein Identification by Capillary Zone Electrophoresis/Microelectrospray Ionization-Tandem Mass Spectrometry at the Subfemtomole Level. Anal Chem.

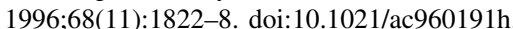

26. Kelly JF, Ramaley L, Thibault P. Capillary Zone Electrophoresis-Electrospray Mass Spectrometry at Submicroliter Flow Rates: Practical Considerations and Analytical Performance. Ana Chem. 1997;69(1):51-60. 100101021/ac9607601.

27. Cai J, Henion J. Capillary electrophoresis-mass spectrometry. J Chromatography A. 1995;703(1-2):667-92. 1001010/021Q673(94)01178-h

28. Severs JC, Smith RD. Electrospray Ionization Mass Spectrometry: Fundamentals, Instrumentation, and Applications. Cole RB, editor. New York: John Wiley \& Sons; 1997.

29. Smith RD, Wahl JH, Goodlett DR, Hofstadler SA. Capillary Electrophoresis/Mass Spectrometry. Anal Chem. 1993;65(13):574A-

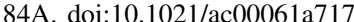

30. Hofstadler SA, Severs JC, Smith RD, Swanek FD, Ewing AG. Analysis of Single Cells with Capillary Electrophoresis Electrospray Ionization Fourier Transform Ion Cycloton Resonance Mass Spectrometry. Rapid Commun Mass Spectrom. 1996;10(8):91922. rem59T>3.0.c0;2-8

101:10.1002/(S1C1)1097-0231(19960610)10:8<919::a1d-

31. Deforce DLD, Raymackers J, Meheus L, Wijnendaele F, Leenheer A, Eeckhout EG. Characterization of DNA Oligonucleotides by Coupling of Capillary Zone Electrophoresis to Electrospray Ionization Q-TOF Mass Spectrometry. Anal Chem. 1998;70(14):3060-8. doi:10.102/ac980147x.

32. McComb ME, Krutchinsky AN, Ens W, Standing KG, Perreault H. Sensitive high-resolution analysis of biological molecules by capillary zone electrophoresis coupled with reflecting time-offlight mass spectrometry. J Chromatography A. 1998;800(1):1-11. doi:10.1016/s0021-9673(97)01158-8.

33. Zhang H, Caprioli RM. Direct Analysis of Aqueous Samples by Matrix-assisted Laser Description Ionization Mass Spectrometry Using Membrane Targets Precoated with Matrix. J Mass Spectrom. 1996;31(6):690-2. 001:10.1002/(S1C1)10968888(199606)31:6<690::aid-jms349>3.0.co;2-2

34. Kašička V. Recent advances in capillary electrophoresis and capillary electrochromatography of peptides. Electrophoresis. 2003;24(2223):4013-46. doi:10.1002/elps.200305660.

35. Hutterer K, Dolník V. Capillary electrophoresis of proteins Electrophoresis. 2001;24:3998-4012.

36. Hernández-Borges J, Neusüß C, Cifuentes A, Pelzing M. Online capillary electrophoresis-mass spectrometry for the analysis of biomolecules. Electrophoresis. 2004;25(14):2257-81. doi:10.1002/elps.200405954

37. Stutz H. Advances in the analysis of proteins and peptides by capillary electrophoresis with matrix-assisted laser desorption/ionization and electrospray-mass spectrometry detection. Electrophoresis. 2005;26(7-8):1254-90. do1:10.1002/elps.200410130.

38. Monton MRN, Terabe S. Recent Developments in Capillary Electrophoresis-Mass Spectrometry of Proteins and Peptides. Anal Sci. 2005;21(1):5-13. do:-10216/analsci.21.5

39. Yamashita M, Fenn JB. Electrospray ion source. Another variation on the free-jet theme. $J$ Phys Chem. 1984;88(20):4451-9. doi:10.1021/150664a002

40. Stolz A, Jooß K, Höcker O, Römer J, Schlecht J, Neusüß C Recent advances in capillary electrophoresis-mass spectrometry: Instrumentation, methodology and applications. Electrophoresis. 2019;40(1):79-112. do1:10.1002/elps.201800331.

41. Nilsson SL, Bylund D, Jörntén-Karlsson M, Petersson P, Markides KE. A chemometric study of active parameters and their interaction effects in a nebulized sheath-liquid electrospray interface for capillary electrophoresis-mass spectrometry. Electrophoresis. 2004;25(13):2100-7. do1:10.1002/elps.200305937.

42. Bateman KP, White RL, Thibault P. Disposable Emitters for On-line Capillary Zone Electrophoresis/Nanoelectrospray Mass Spectrometry. Rapid Commun Mass Spectrom. 1997;11(3):30715. doi:10.1002/(Sici)1097-0231(19970215)11:3<307::aidrcm850>3.0.co;2-m

43. Mazereeuw M, Hofte AJP, Tjaden UR, Greef J. A novel sheathless and electrodeless microelectrospray interface for the on-line coupling of capillary zone electrophoresis to mass spectrometry. Rapid Commun Mass Spectrom. 1997;11(9):981-6. do1:10.1002/(S1C1)10977 0231(19970615)11:9<981::aid-rcm901>3.0.co;2-s.

44. Lee ED, Mück W, Henion JD, Covey TR. Liquid junction coupling for capillary zone electrophoresis/ion spray mass spectrometry. Biol Mass Spectrom. 1989;18(9):844-50. 10010.1002/hms.1200180932.

45. Foret F, Kirby DP, Karger BL. Proceedings of the 44th ASMS Conference on MS and Allied Topics; 1996. p. 913.

46. Fanali S, D'Orazio G, Foret F, Kleparnik K, Aturki Z. On-line CEMS using pressurized liquid junction nanoflow electrospray interface and surface-coated capillaries. Electrophoresis. 2006;27(23):4666-73. 
do1:10.1002/elps.200600322

47. Vanhoutte K, Dongen W, Esmans EL. On-line nanoscale liquid chromatography nano-electrospray mass spectrometry: effect of the mobile phase composition and the electrospray tip design on the performance of a nanoflowTM electrospray probe. Rapid Commun Mass Spectrom. 1998;12(1):15-24. d01:10.1002/(S1c1)10970231(1998015)12:1<15::a1d-rcm 111>3.0.co;2-c.

48. Bindila L, Almeida R, Sterling A, Allen M, Peter-Katalini? J, Zamfir A, et al. Off-line capillary electrophoresis/fully automated nanoelectrospray chip quadrupole time-of-flight mass spectrometry and tandem mass spectrometry for glycoconjugate analysis. J Mass Spectrom. 2004;39(10):1190-1201. doi:10.1002/jms.707.

49. Zamfir A, Peter-Katalinic J. Glycoscreening by on-line sheathless capillary electrophoresis/electrospray ionization-quadrupole time of flight-tandem mass spectrometry. Electrophoresis. 2001;22(12):244857. do1:10.1002/1522-2683(200107)22:12<2448::a1d elps2448>3.0.co;2-a

50. Liu CC, Jong R, Covey T. Coupling of a large-size capillary column with an electrospray mass spectrometer: A reliable and sensitive sheath flow capillary electrophoresis-mass spectrometry interface. $J$ Chromatogr A. 2003;1013(1-2):9-18.

51. Fernández FM, Vadillo JM, Kimmel JR, Wetterhall M, Markides K, Rodriguez N, et al. Hadamard Transform Timeof-Flight Mass Spectrometry: A High-Speed Detector for Capillary-Format Separations. Anal Chem. 2002;74(7):1611-7. doi:10.102/ac0156730.

52. Gao H, Shen Y, Veenstra TD, Harkewicz R, Anderson GA, Bruce JE, et al. Two-dimensional electrophoretic/chromatographic separations combined with electrospray ionization FTICR mass spectrometry for high throughput proteome analysis. J Microcolumn Separations. 2000;12(7):383-90. do1:10.1002/1520-667x(2000)12:7<383::aidmcs $1>3.0 . \mathrm{co} ; 2-\mathrm{s}$

53. Bergström SK, Dahlin AP, Ramström M, Andersson M, Markides KE, Bergquist J. A simplified multidimensional approach for analysis of complex biological samples: on-line LC-CE-MS. Analyst. 2006;131(7):791-8. d01:10.1039/6601660].

54. Smith RD. Evolution of ESI-mass spectrometry and Fourier transform ion cyclotron resonance for proteomics and other biological applications. Int J Mass Spectrom. 2000;200(1-3):509-44.

55. Zürbig P, Renfrow MB, Schiffer E, Novak J, Walden M, Wittke S, et al. Biomarker discovery by CE-MS enables sequence analysisvia MS/MS with platform-independent separation. Electrophoresis. 2006;27(11):2111-25. do1:10.1002/elps.200500827.

56. Paša-Tolić L, Masselon C, Barry RC, Shen Y, Smith RD. Proteomic analyses using an accurate mass and time tag strategy. BioTechniques. 2004;37(4):621-39. 10i:1022 44/04374rv0].

57. Michael SM, Chien BM, Lubman DM. Detection of electrospray ionization using a quadrupole ion trap storage/reflectron timeof-flight mass spectrometer. Anal Chem. 1993;65(19):2614-20.

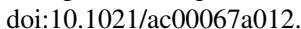

58. Wu JT, Qian MG, Li MX, Liu L, Lubman DM. Use of an Ion Trap Storage/Reflectron Time-of-Flight Mass Spectrometer as a Rapid and Sensitive Detector for Capillary Electrophoresis in Protein Digest Analysis. Anal Chem. 1996;68(19):3388-96. 106:1021/ac960405y.

59. Hofstadler SA, Wahl JH, Bruce JE, Smith RD. On-line capillary electrophoresis with Fourier transform ion cyclotron resonance mass spectrometry. 1993;115:6983-4. do1:10.1021/ja00068a070

60. Senko MW, Hendrickson CL, Emmett MR, Shi SDH, Marshall AG. External accumulation of ions for enhanced electrospray ionization fourier transform ion cyclotron resonance mass spectrometry. $J$ Am Soc Mass Spectrom. 1997;8(9):970-6. 10:101016/s10440305(97)00126-8.

61. Belov ME, Anderson GA, Angell NH, Shen Y, Tolic N, Udseth HR, et al. Dynamic Range Expansion Applied to Mass Spectrometry Based on Data-Dependent Selective Ion Ejection in Capillary Liquid Chromatography Fourier Transform Ion Cyclotron Resonance for Enhanced Proteome Characterization. Anal Chem. 2001;73(21):5052_ 60. 10ن:10.102/ac)

62. Cifuentes A, Poppe H. Behavior of peptides in capillary electrophoresis: Effect of peptide charge, mass and structure.

Electrophoresis.

$1997 ; 18(12-13): 2362-76$ do1:10.1002/elps.1150181227.

63. Tessier B, Schweizer M, Fournier F, Framboisier X, Chevalot I, Vanderesse R, et al. Prediction of the amino acid composition of small peptides contained in a plant protein hydrolysate by LC-MS and CE-MS. Food Res Int. 2005;38(5):577-84. do1:10.1016/].foodres.2004.11.01].

64. Simó C, Cifuentes A. Capillary electrophoresis-mass spectrometry of peptides from enzymatic protein hydrolysis: Simulation and optimization. Electrophoresis. 2003;24(5):834-42. do1:10.1002/elps.200390105

65. Klampfl CW. Review coupling of capillary electrochromatography to mass spectrometry. J Chromatography A. 2004;1044(1-2):131-44. do1:10.1016/j.chroma.2004.04.072

66. Guek M, Gaspari M, Walhagen K, Vreeken RJ, Verheij ER, Greef J. Capillary electrochromatography/nanoelectrospray mass spectrometry for attomole characterization of peptides. Rapid Commun Mass Spectrom. 2000;14(16):1448-54. 10i-10.1002/10970231(20000830)14:16<1448::aid-rcm44>3.0.c0;2-9

67. Storms HF, Heijden R, Tjaden UR, Greef J. Optimization of protein identification from digests as analyzed by capillary isoelectric focusing-mass spectrometry. J Chromatogr B Anal Technol Biomed Life Sci. 2005;824(1-2):189-200.

68. Kuroda Y, Yukinaga H, Kitano M, Noguchi T, Nemati M, Shibukawa A, et al. On-line capillary isoelectric focusing-mass spectrometry for quantitative analysis of peptides and proteins. J Pharm Biomed Anal. 2005;37(3):423-8. do1:10.1016/1.jpba.2004.11.025

69. Loo JA, Udseth HR, Smith RD. Peptide and protein analysis by electrospray ionization-mass spectrometry and capillary electrophoresis-mass spectrometry. Anal Biochem. 1989;179(2):40412. do1:10.1016/0003-2697(89)90153-x.

70. Kaiser T, Wittke S, Just I, Krebs R, Bartel S, Fliser D. Capillary electrophoresis coupled to mass spectrometer for automated and robust polypeptide determination in body fluids for clinical use Electrophoresis. 2004;25(13):2044-55. do1:10.1002/elps.200305788.

71. Kaiser T, Kamal H, Rank A, Kolb HJ, Holler E, Ganser A, et al. Proteomics applied to the clinical follow-up of patients after allogeneic hematopoietic stem cell transplantation. Blood. 2004;104(2):340-9. doi:-10. 182/600d-2004-(02-0518.

72. Weissinger EM, Nguyen-Khoa T, Fumeron C, Saltiel C, Walden $\mathrm{M}$, Kaiser $\mathrm{T}$, et al. Effects of oral vitaminC supplementation in hemodialysis patients: A proteomic assessment. Proteomics. 2006;6(3):993-1000. d01:10.1002/pmic.200500210

73. Wittke S, Fliser D, Haubitz M, Bartel S, Krebs R, Hausadel F, et al. Determination of peptides and proteins in human urine with capillary electrophoresis-mass spectrometry, a suitable tool for the establishment of new diagnostic markers. J Chromatography A. 2003;1013(1-2):173-81. doi:10.1016/s0021-9673(03)00713-1.

74. Moini M, Demars SM, Huang H. Analysis of Carbonic Anhydrase in Human Red Blood Cells Using Capillary Electrophoresis/Electrospray Ionization-Mass Spectrometry. Anal Chem. 2002;74(15):3772-6. dol:10.1021/ac0200227.

75. Stutz H, Bordin G, Rodriguez AR. Capillary zone electrophoresis of metal-binding proteins in formic acid with UV- and mass spectrometric detection using cationic transient capillary isotachophoresis for preconcentration. Electrophoresis. 2004;25(78):1071-89. do1:10.1002/elps.200305806

76. Kaiser T, Hermann A, Kielstein JT, Wittke S, Bartel S, Krebs R, et al. Capillary electrophoresis coupled to mass spectrometry to establish polypeptide patterns in dialysis fluids. J Chromatography A. 2003;1013(1-2):157-71. doi:10.1016/s0021-9673(03)00712-X

77. Wittke S, Mischak H, Walden M, Kolch W, Rädler T, Wiedemann K. Discovery of biomarkers in human urine and cerebrospinal fluid by capillary electrophoresis coupled to mass spectrometry: Towards new diagnostic and therapeutic approaches. Electrophoresis. 2005;26(78):1476-87. do1:10.1002/elps.200410140.

78. Kim J, Zand R, Lubman DM. Electrophoretic mobility for peptides with post-translational modifications in capillary electrophoresis. 
Electrophoresis. 2003;24(5):782-93. 001:10.1002/elps.200390098

79. Yoo C, Pal M, Miller FR, Barder TJ, Huber C, Lubman DM. Toward high sequence coverage of proteins in human breast cancer cells using on-line monolith-based HPLC-ESI-TOF MS compared to CE MS Electrophoresis. 2006;27(11):2126-38. doi:10.1002/elps.200500651.

80. Hu A, Chen CT, Tsai PJ, Ho YP. Using capillary electrophoresisselective tandem mass spectrometry to identify pathogens in clinical samples. Anal Chem. 2006;78(14):5124-33.

81. Zhang B, Foret F, Karger BL. A Microdevice with Integrated Liquid Junction for Facile Peptide and Protein Analysis by Capillary Electrophoresis/Electrospray Mass Spectrometry. Anal Chem. 2000;72(5):1015-22. 10i:10.102//ac991507.

82. Simó C, González R, Barbas C, Cifuentes A. Combining Peptide Modeling and Capillary Electrophoresis-Mass Spectrometry for Characterization of Enzymes Cleavage Patterns: Recombinant versus Natural Bovine Pepsin A. Anal Chem. 2005;77(23):7709-16. doi:10.102]/ac051067d.

83. Dolnik V, Liu S. Applications of capillary electrophoresis on microchip. $J$ Separation Sci. 2005;28(15):1994-2009. do1:10.1002//ssc.200500243

84. Sung WC, Makamba H, Chen SH. Chip-based microfluidic devices coupled with electrospray ionization-mass spectrometry. Electrophoresis. 2005;26(9):1783-91. 001:10.1002/elps.200410346

85. DeVoe DL, Lee CS. Microfluidic technologies for MALDIMS in proteomics. Electrophoresis. 2006;27(18):3559-68. doi:10.1002/elps.200600224

86. Fujita M, Hattori W, Sano T, Baba M, Someya H, Miyazaki $\mathrm{K}$, et al. High-throughput and high-resolution two dimensional mapping of $\mathrm{pI}$ and $\mathrm{m} / \mathrm{z}$ using a microchip in a matrixassisted laser desorption/ionization time-of-flight mass spectrometer. $\quad J$ Chromatography A. 2006;1111(2):200-5. doi:10.1016/].chroma.2005.11.117

87. Marinas M, Sa E, Rojas MM, Moalem M, Urbano FJ, Guillou C. A nuclear magnetic resonance $(1 \mathrm{H}$ and $13 \mathrm{C}$ ) and isotope ratio mass spectrometry ( d 13 C , d $2 \mathrm{H}$ and d $18 \mathrm{O}$ ) study of Andalusian olive oils. Rapid Commun Mass Spectrom. 2010;24:1457-66.

88. Wen J, Lin Y, Xiang F, Matson DW, Udseth HR, Smith RD Microfabricated isoelectric focusing device for direct electrospray ionization-mass spectrometry. Electrophoresis. 2000;21(1):1917. elps191>3.0.co;2-m doi:10.1002/(Sici) $1522-2683(20000101) 21: 1<191::$ aid-

89. Neusüß C, Pelzing M, Macht M. A robust approach for the analysis of peptides in the low femtomole range by capillary electrophoresistandem mass spectrometry. Electrophoresis. 2002;23(18):3149-59. do1:10.1002/1522-2683(200209)23:18<3149::a1d-elps3149>3.0.co;2-

90. Sandra K, Lynen F, Devreese B, Beeumen J, Sandra P. Oncolumn sample enrichment for the high-sensitivity sheath-flow CE-
MS analysis of peptides. Anal Bioanalytical Chem. 2006;385(4):6717. doi:10.1007/s00216-006-0461-y.

91. Janini GM, Conrads TP, Wilkens KL, Issaq HJ, Veenstra TD. A Sheathless Nanoflow Electrospray Interface for On-Line Capillary Electrophoresis Mass Spectrometry. Anal Chem. 2003;75(7):1615-9.

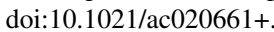

92. Chien RL, Helmer JC. Electroosmotic properties and peak broadening in field-amplified capillary electrophoresis. Anal Chem. 1991;63(14):1354-61. 10i:10.102/ac00014a004.

93. Yang Y, Boysen RI, Hearn MTW. Optimization of FieldAmplified Sample Injection for Analysis of Peptides by Capillary Electrophoresis-Mass Spectrometry. Anal Chem. 2006;78(14):4752-

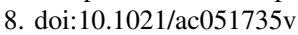

94. Larsson M, Lutz ESM. Transient isotachophoresis for sensitivity enhancement in capillary electrophoresis-mass spectrometry for peptide analysis. Electrophoresis. 2000;21(14):285965. 10i:10.1002/1522-2683(20000801)21:14<2859::aid-

\section{elps2859>3.0.co;2-1}

\section{Author biography}

Umang Shah, Assistant Professor (1) https://orcid.org/0000-0001-67482137

Aarti Patel, Student

Rutu Patel, Student

Mehul Patel, Associate Professor

Ashish Patel, Assistant Professor

Mansukh Kavad, ADL Scientist

Esha Desai, Assistant Professor

Cite this article: Shah U, Patel A, Patel R, Patel M, Patel A, Kavad M, Desai E. Overview on capillary electrophoresis with mass spectrometry: Application in peptide analysis and proteomics. Int J Pharm Chem Anal 2021;8(1):6-15. 